\title{
Association Between hsa-miR-30e Polymorphisms and Sporadic Primary Hyperparathyroidism Risk
}

\author{
MARIA MIZAMTSIDI ${ }^{1}$, KONSTANTINOS NASTOS $^{1}$, FAUSTO PALAZZO ${ }^{2}$, \\ VASILIS CONSTANTINIDES ${ }^{2}$, ROBERTO DINA ${ }^{3}$, MEGAN FARENDEN ${ }^{4}$, \\ GEORGE MASTORAKOS $^{5}$, IOANNIS VASSILIOU ${ }^{1}$ and MARIA GAZOULI ${ }^{4}$ \\ ${ }^{1}$ Endocrine Surgery Unit, Second Department of Surgery, \\ Aretaieion University Hospital, National and Kapodistrian University of Athens, Athens, Greece; \\ ${ }^{2}$ Department of Thyroid and Endocrine Surgery, Faculty of Medicine, \\ Imperial College London, Hammersmith Hospital, London, U.K.; \\ ${ }^{3}$ Department of Pathology, Imperial College Healthcare NHS Trust, Hammersmith Hospital, London, U.K.; \\ ${ }^{4}$ Laboratory of Biology, School of Medicine, National and Kapodistrian University of Athens, Athens, Greece; \\ ${ }^{5}$ Unit of Endocrinology, Diabetes and Metabolism, Aretaieion University Hospital, \\ National and Kapodistrian University of Athens, Athens, Greece
}

\begin{abstract}
Background/Aim: Almost 15\% of patients with sporadic primary hyperparathyroidism ( $s P H P T)$ present with multiple gland disease (MGD). The aim of this study was to investigate the potential role of two polymorphisms of the hsa-miR-30e, in sPHPT tumorigenesis. Patients and Methods: One-hundred twenty sPHPT patients, 77 presenting a single adenoma and 43 with MGD, and 54 healthy controls were genotyped. The SNPs were identified using the allelespecific PCR methodology, while the hsa-miR-30e expression was analyzed by real-time quantitative reverse transcriptase PCR. Results: Hsa-miR-30e expression was found to be significantly higher in patients with MGD compared to patients with single adenomas ( $p=0.0019)$, but no differences were found regarding specific genotype carriers. The genotype frequencies for ss 178077483 and rs 7556088 were significantly different between patients and healthy controls. Conclusion: Although the polymorphisms cannot be used as biomarkers for the differential diagnosis of MGD, hsa-miR30e expression could potentially serve as a biomarker for this purpose.
\end{abstract}

This article is freely accessible online.

Correspondence to: Maria Mizamtsidi, MD, MSc, Endocrine Surgery Unit, Second Department of Surgery, Aretaieion University Hospital, National and Kapodistrian University of Athens, 56 Vasilisis Sofias Avenue, 11528, Athens, Greece. Tel: +30 2107286130, e-mail: maria_mizamtsidi1@yahoo.gr

Key Words: Sporadic primary hyperparathyroidism, adenoma, multiple gland disease, microRNA.
Primary hyperparathyroidism (PHPT) is characterized by excessive production and release of parathyroid hormone by the parathyroid glands. Sometimes more than one gland can be abnormal and the pathology ranges from double adenomas to diffuse hyperplasia of the parathyroid glands, and all fall under the umbrella term of multiple gland disease (MGD). MGD cannot be reliably diagnosed preoperatively in SPHPT and the distinction of the abnormal gland(s) still depends on the experience of the surgeon, as objective factors have not been identified (1-4), thus presenting the risk of either over or under treatment. Overtreatment may result in permanent hypoparathyroidism, while undertreatment in disease persistence or recurrence.

No predictive genetic screening tests are currently available to distinguish adenomas from MGD in SPHPT (5). Moreover, multiple mutations have been implicated, making diagnosis even more difficult (6). Although there are specific pathways involved in adenoma tumorigenesis, there are few data concerning the MGD pathway in SPHPT (7-15).

miRNAs have unique features suitable for biomarker use, including an exceptional stability against degradation and easy extraction from various specimens including tissues, blood, faeces etc. (16). miRNAs have a regulatory role in cellular processes such as apoptosis, proliferation and differentiation by affecting gene expression. Differential expression of miRNAs has been reported for various tumor entities (16). Furthermore, the expression of miRNAs may be affected by the presence of specific single nucleotide polymorphisms (SNPs) (17). SNPs in miRNA target sites may affect miRNA-binding resulting in differential expression of miRNAs and consequently differential gene expression and development of disease $(18,19)$. 
Very few studies have examined the role of miRNAs in parathyroid neoplasia $(9,20,21)$, and most focus on the differential expression of miRNAs in parathyroid carcinoma. Rahbari et al. have found 22 uniquely expressed miRNAs in 15 sporadic primary parathyroid MGD samples (21). We cross-matched miRNAs that are found in databases mirOntology, miRbase, miRTarBase and TargetScan to be associated with genes overexpressed in $\operatorname{sPHPT} \operatorname{MGD}(9,20)$. This cross-matching, indicated that the most commonly associated miRNA was hsa-miR-30e. Numerous SNPs have been identified in this miRNA, with ss 178077483 and rs 7556088 being two of the most studied ones.

To date, there is no study on the role of miRNAs in the regulation of the molecular pathways leading to adenomas and MGD in SPHPT. Differences in the expression of hsamiR-30e between patients with single adenomas and MGD in SPHPT was the main endpoint of our study. In addition, the association of hsa-miR-30e SNPs with sporadic primary adenomas or MGD was evaluated.

\section{Materials and Methods}

Patients. This was a collaborative retrospective study from two endocrine surgery departments: The Department of Thyroid and Endocrine Surgery, Hammersmith Hospital, Imperial College London, UK and the Endocrine Surgery Unit, Second Department of Surgery, Aretaieion University Hospital, Athens, Greece. Patient databases were retrospectively reviewed. The data of patients aged 18-70 years who had undergone parathyroidectomy and found to have sporadic primary MGD or adenomas according to the pathological diagnosis were extracted. Patients with secondary hyperparathyroidism or patients with genetic syndromes involving PHPT, familiar hereditary disease or history of other malignancies were excluded. Patients with single adenomas were included only if they were followed-up for at least 2 years and confirmed to be disease-free.

Finally, 120 patients were included in the study, 43 patients with MGD and 77 patients with single parathyroid adenomas. In addition, 54 healthy adults served as normal controls. The control group was tested and found to be negative for PHPT. Parathyroid tissues received from patients with adenomas or MGD and blood samples from the healthy controls were used. Clinical data were collected from both Institutions' databases.

The study was approved by the Scientific Committee of the Medical School of Athens (National and Kapodistrian University of Athens, Approval No B-30/27-02-2014) and found to be in accordance with all medical and bioethical issues of the Institution. Handling samples of human tissues was in accordance with the bioethics committees of both Institutions. Patients had given their informed consent preoperatively for the possibility their tissues might be used for scientific purposes.

Clinical and Biochemical Data. Collected data included patientrelated demographics (age, gender), clinical data (history of head and neck radiation exposure, absence of hereditary disease), biochemical parameters [pre- and post-operative levels of calcium, phosphate, parathyroid hormone (PTH), Vitamin D levels [25(OH)D3]] and histopathological data.
Genotyping. Genomic DNA was extracted from parathyroid formalin fixed and paraffin embedded (FFPE) tissues using the PureLink Genomic DNA Kit (Invitrogen Inc, Rockville, MD) according to the manufacturer's instructions, after a deparaffinization step using xylene followed by ethanol washes (22). The ss 178077483 and rs7556088 found in hsa-miR-30e miRNA were determined by allele-specific PCR. Primers sequences were:

ss 178077483F: 5'-GCGTCTCCGTTCTTTCTGGG-3', ss17807748 3RC: 5'CATCCGACTGAAAGCTCCTCTG-3', ss178077483RT: 5'-CATCCGACTGAAAGCTCCTCTA-3', and rs7556088FC: 5'GATTGCATGATTCACTAGGTCC-3', rs7556088FT: 5'-GATTG CATGATTCACTAGGTCT-3', rs7556088R: 5'-TTAATACAGGCT GGGATGGG-3'.

The products were analyzed by electrophoresis on a $3 \%$ agarose gel and visualized using UV fluorescence after staining with ethidium bromide.

Expression. The expression of hsa-miR-30e was examined in 10 representative fresh biopsy tissue samples that were available, 5 of parathyroid adenomas and of 5 MGD tissues, and found to be homozygous for the wild type or the polymorphisms. Total RNA was extracted from fresh tissues using the miRNeasy Kit (Qiagen, Hamburg, Germany). The stem-loop quantitative Reverse Transcriptase-Polymerase Chain Reaction (qRT-PCR) was used to determine the expression of the hsa-mir-30e and the small nuclear RNA U6 (23).

The RT primers were 5'-GTCGTATCCAGTGCAGGGTCCGA GGT ATTCGCACTGGATACGACCTTCCA-3' or hsa-mir-30e and 5'AAC GCTTCACGAATTTGCGT-3' for U6. Primers of 5'-GTGCA GGGTCCGAGGT-3' and 5'-GCTGTGTAAACATCCTTGACTGG-3' were used to amplify has-mir-30e, and 5'-CTCGCTTCGGCAGCACA3' and 5'-AACGCTTCACGAATTTGCGT-3' were used to amplify U6 as previously described (24). All real-time reactions, including notemplate controls, were run in duplicate using the ABI 7500 Real-Time PCR System (Applied Biosystems, Foster City, CA, USA). The comparative $\mathrm{Ct}\left(2^{-\Delta \Delta \mathrm{CT}}\right)$ method was used for quantification of transcripts.

Relative expression of the has-mir-30e was calculated by normalization with U6 gene expression.

Statistical analysis. Chi square test and Fischer's exact test were used to compare frequencies of alleles between the groups. Experiments were conducted in triplicate. Correlations between miRNA polymorphisms and clinicopathological parameters were also statistically analyzed. All statistical analyses were carried out using SPSS for Windows 20.0. Probability values of $<0.05$ were considered significant.

\section{Results}

There was no difference in sex distribution and age between adenomas and MGD groups (as an absolute value or a subgroup allocation-under $65 \mathrm{vs}$. over 65 years of age). However, there was a statistically significant difference in the mean age of the control group $(52.06 \pm 14.59)$ compared with patients with adenomas $(59.88 \pm 10.8, p<0.0001)$ or MGD $(61.81 \pm 13.74, p<0.0001)$. In addition, there was a statistically significant difference in gender distribution when 
Table I. Patient demographics.

\begin{tabular}{|c|c|c|c|c|c|c|}
\hline & $\begin{array}{l}\text { Adenoma } \\
\mathrm{N}=77\end{array}$ & $\begin{array}{l}\text { MGD } \\
\mathrm{N}=43\end{array}$ & $\begin{array}{c}\text { Sig. } \\
\text { Ademona } v s . \text { MGD }\end{array}$ & $\begin{array}{l}\text { Control } \\
\mathrm{N}=54\end{array}$ & $\begin{array}{c}\text { Sig. } \\
\text { Adenoma } v s . \text { Control }\end{array}$ & $\begin{array}{c}\text { Sig. } \\
\text { MGD vs. Control }\end{array}$ \\
\hline \multicolumn{7}{|l|}{ Gender } \\
\hline Male & $15(19.5 \%)$ & $8(18.6 \%)$ & $p=0.907$ & $19(35.2 \%)$ & $p=0.044$ & $p=0.070$ \\
\hline Female & $62(80.5 \%)$ & $35(81.4 \%)$ & & $35(64.8 \%)$ & & \\
\hline \multicolumn{7}{|l|}{ Age subgroup } \\
\hline Under 65 (years old) & $53(68.8 \%)$ & $24(55.8 \%)$ & $p=0.154$ & $42(77.8 \%)$ & $p=0.259$ & $p=0.021$ \\
\hline Over 65 (years old) & $24(31.2 \%)$ & $19(44.2 \%)$ & & $12(22.2 \%)$ & & \\
\hline Age (years) & $59.88 \pm 10.8$ & $61.81 \pm 13.74$ & $p=0.399$ & $52.06 \pm 14.59$ & $p=0.001$ & $p=0.001$ \\
\hline
\end{tabular}

Table II. Biochemical parameters.

\begin{tabular}{lcccccc}
\hline & $\begin{array}{c}\text { Adenoma } \\
\mathrm{N}=77\end{array}$ & $\begin{array}{c}\text { MGD } \\
\mathrm{N}=43\end{array}$ & $\begin{array}{c}\text { Sig } \\
\text { ademona } v s \text {. MGD }\end{array}$ & $\begin{array}{c}\text { Control } \\
\mathrm{N}=54\end{array}$ & $\begin{array}{c}\text { Sig. } \\
\text { adenoma } v s . \text { control }\end{array}$ & $\begin{array}{c}\text { Sig. } \\
\text { MGD } v s . \text { control }\end{array}$ \\
\hline Calcium (mg/dl) & $11.28 \pm 0.97$ & $11.18 \pm 0.53$ & $p=0.492$ & $9.37 \pm 0.31$ & $p<0.0001$ & $p<0.0001$ \\
Phosphate (mg/dl) & $2.73 \pm 0.42$ & $2.58 \pm 0.39$ & $p=0.067$ & $3.59 \pm 0.53$ & $p<0.0001$ & $p<0.0001$ \\
PTH (pg/ml) & $176.6 \pm 183.9$ & $198.8 \pm 127.3$ & $p=0.484$ & $37 \pm 14.23$ & $p<0.0001$ & $p<0.0001$ \\
$25(\mathrm{OH}) \mathrm{D} 3(\mathrm{ng} / \mathrm{ml})$ & $20.69 \pm 8.12$ & $20.33 \pm 7.28$ & $p=0.811$ & $37.75 \pm 10.25$ & $p<0.0001$ & $p<0.0001$ \\
$\begin{array}{l}\text { Affected gland(s) } \\
\text { maximum weight (gr) }\end{array}$ & $1.14 \pm 1.25$ & $1.22 \pm 1.49$ & $p=0.760$ & Not applicable & Not applicable & Not applicable \\
$\begin{array}{l}\text { Affected gland(s) } \\
\text { maximum size }(\mathrm{cm})\end{array}$ & $1.78 \pm 1.04$ & $2.08 \pm 2.41$ & $p=0.341$ & Not applicable & Not applicable & Not applicable \\
\hline
\end{tabular}

comparing patients with adenomas to healthy subjects and a different age subgroup allocation between patients with MGD and the control group. All demographic details are listed in Table I.

As expected, serum calcium, phosphate, plasma PTH and $25(\mathrm{OH}) \mathrm{D} 3$ concentrations were significantly different in patients with adenomas or MGD compared with controls $(p<0.0001)$. When comparing patients with adenomas and MGD, there was no significant difference in these parameters. There was also no difference between weight and size of the resected glands in these two groups. The biochemical parameters analyzed are presented in Table II.

hsa-miR-30e expression levels were significantly higher in MGD patients than in adenoma patients independently of the polymorphisms ( $p=0.019$, Figure 1$)$. The limited number of samples used for the expression analysis was due to the rarity of the disease and the availability of fresh biopsy tissues. However, despite the small number of samples tested and the potential influence of selection bias, reproducible results were obtained.

The genotype and allele frequencies of the ss 178077483 polymorphism are presented in Table III. Although the ss $178077483 \mathrm{C} / \mathrm{T}$ genotype carriers did not differ between the adenoma and MGD patients' groups $(p=0.18, \mathrm{OR}=1.74$,

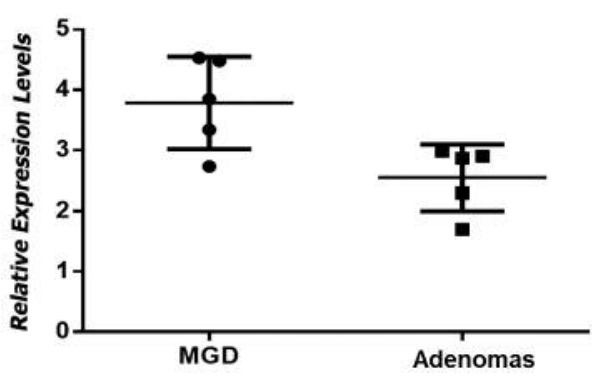

Figure 1. Relative expression levels of hsa-miR-30e in PHPT patients with adenomas and MGD.

95\% $\mathrm{CI}=0.80-3.76$ ), there was a significant difference when comparing PHPT patients with the control group (adenoma $v s$. control group, $p \leq 0.0001, \mathrm{OR}=11.58,95 \% \mathrm{CI}=4.13-32.45$ and MGD $v s$. control group, $p=0.0005, \quad \mathrm{OR}=6.67$, 95\% CI=2.2-20.17).

As for ss $178077483 \mathrm{~T} / \mathrm{T}$ genotype frequency, there was no statistically significant difference in the frequency of the ss178077483 T/T genotype between adenoma and MGD patients' groups $(p=0.39, \mathrm{OR}=3.79,95 \% \mathrm{CI}=0.41-34.51)$ or between MGD patients and the control group $(p=0.35$, 
in vivo $33: 1263-1269$ (2019)

Table III. Frequencies of the allele presence in SNPs ss 178077483 and rs7556088 of hsa-miR-30e.

\begin{tabular}{|c|c|c|c|c|c|c|c|c|c|}
\hline SNPs & $\begin{array}{l}\text { Adenoma } \\
\mathrm{N}=77\end{array}$ & $\begin{array}{l}\text { MGD } \\
\mathrm{N}=43\end{array}$ & $\begin{array}{c}p \text { adenoma } \\
v s . \text { MGD }\end{array}$ & $\begin{array}{l}\text { Adenoma } v s . \\
\text { MGD } \\
\text { OR } 95 \% \mathrm{CI}\end{array}$ & $\begin{array}{c}\text { Control } \\
\mathrm{N}=54\end{array}$ & $\begin{array}{c}p \text { adenoma } \\
v s . \text { control }\end{array}$ & $\begin{array}{l}\text { Adenoma } \\
\text { vs. control } \\
\text { OR } 95 \% \mathrm{CI}\end{array}$ & $\begin{array}{l}\text { Sig. MGD } \\
\text { vs. control }\end{array}$ & $\begin{array}{l}\text { MGD vs. } \\
\text { control } \\
\text { OR 95\%CI }\end{array}$ \\
\hline \multicolumn{10}{|l|}{ ss 178077483} \\
\hline $\mathrm{C} / \mathrm{C}$ & $33(42.9 \%)$ & $25(58.1 \%)$ & 1 (Ref.) & $1.74 ; 0.80-3.76$ & $49(90.7 \%)$ & 1 (Ref.) & 11.58 & 1 (Ref.) & $6.67 ; 2.2-20.17$ \\
\hline $\mathrm{C} / \mathrm{T}$ & $39(50.6 \%)$ & $17(39.5 \%)$ & 0.18 & $3.79 ; 0.41-34.51$ & $5(9.3 \%)$ & $<0.0001$ & $4.13-32.45$ & 0.0005 & $5.82 ; 0.23-$ \\
\hline $\mathrm{T} / \mathrm{T}$ & $5(6.5 \%)$ & $1(2.3 \%)$ & 0.39 & & $0(0 \%)$ & 0.014 & $16.25 ; 0.87-304.03$ & 0.35 & 148.23 \\
\hline $\begin{array}{l}\text { ss } 178077483 \\
\text { C Allele }\end{array}$ & $105(68.18 \%)$ & $67(77.91 \%)$ & 1 (Ref.) & $\begin{array}{c}1.64 \\
0.89-3.03\end{array}$ & $103(95.37 \%)$ & 1 (Ref.) & $\begin{array}{c}9.61 ; \\
3.68-25.1\end{array}$ & 1 (Ref.) & $5.84 ; 2.08-16.4$ \\
\hline $\begin{array}{l}\text { ss178077483 } \\
\text { T Allele }\end{array}$ & $49(31.82 \%)$ & $19(22.09 \%)$ & 0.13 & & $5(4.63 \%)$ & $<0.0001$ & & 0.0003 & \\
\hline \multicolumn{10}{|l|}{ rs7556088 } \\
\hline $\mathrm{C} / \mathrm{C}$ & $47(61 \%)$ & $20(46.5 \%)$ & 1 (Ref.) & $0.52 ; 0.23-1.17$ & $50(92.6 \%)$ & 1 (Ref.) & $5.85 ; 1.88-18.25$ & 1 (Ref.) & $11.25 ; 3.38-37.39$ \\
\hline $\mathrm{T} / \mathrm{C}$ & $22(28.6 \%)$ & $18(41.9 \%)$ & 0.14 & $0.68 ; 0.2-2.33$ & $4(7.4 \%)$ & 0.0008 & 18.07 & $<0.0001$ & $27.1 ; 1.43-513.05$ \\
\hline $\mathrm{T} / \mathrm{T}$ & $8(10.4 \%)$ & $5(11.6 \%)$ & 0.53 & & $0(0 \%)$ & 0.006 & $1.01-322.05$ & 0.003 & \\
\hline $\begin{array}{l}\text { rs7556088 } \\
\text { C Allele }\end{array}$ & $116(75.32 \%)$ & $58(67.44 \%)$ & 1 (Ref.) & $\begin{array}{c}0.68 ; \\
0.38-1.21\end{array}$ & $104(96.3 \%)$ & 1 (Ref.) & $\begin{array}{c}8.51 \\
2.94-24.68\end{array}$ & 1 (Ref.) & $12.55 ; 4.19-37.56$ \\
\hline $\begin{array}{l}\text { rs7556088 } \\
\text { T Allele }\end{array}$ & $38(24.68 \%)$ & $28(32.56 \%)$ & 0.23 & & $4(3.7 \%)$ & $<0.0001$ & & $<0.0001$ & \\
\hline
\end{tabular}

$\mathrm{OR}=5.82,95 \% \mathrm{CI}=0.23-148.23)$. However, adenoma patients had a higher frequency of the ss $178077483 \mathrm{~T} / \mathrm{T}$ genotype compared to the control group $(p=0.014, \quad \mathrm{OR}=16.25$, $95 \% \mathrm{CI}=0.87-304.03)$.

The frequency of ss178077483 $\mathrm{T}$ allele was not found to be significantly different between adenoma and MGD patients $(p=0.13, \mathrm{OR}=1.64,95 \% \mathrm{CI}=0.89-3.03)$. However, it differed significantly when comparing adenoma or MGD patients with the control group $(\mathrm{p} \leq 0.0001, \mathrm{OR}=9.61$, $95 \% \mathrm{CI}=3.68-25.1$ and $p=0.0003, \mathrm{OR}=5.84,95 \% \mathrm{CI}=2.08$ 16.4 , respectively).

Regarding the rs7556088 polymorphism, the frequency of rs7556088 T/C genotype carriers did not differ between adenoma and MGD patients $(p=0.14, \mathrm{OR}=0.52,95 \% \mathrm{CI}=0.23$ 1.17). However, there was statistically significant difference between any group of PHPT patients and the control group (adenoma $v s$. control group, $p=0.0008, \mathrm{OR}=5.85,95 \% \mathrm{CI}=1.88$ 18.25 and MGD vs. control group, $\mathrm{p} \leq 0.0001, \mathrm{OR}=11.25$, 95\% CI=3.38-37.39).

The same statistical pattern was observed when examining the rs7556088 T/T genotype frequency. There was no statistically significant difference between adenoma and MGD patients $(p=0.53, \mathrm{OR}=0.68,95 \% \mathrm{CI}=0.2-2.33)$, but there was a statistically significant difference between any group of PHPT patients and the control group (adenoma vs. control group, $p=0.006, \mathrm{OR}=18.07,95 \% \mathrm{CI}=1.01-322.05$ and $\mathrm{MGD}$ vs. control group, $p=0.003, \mathrm{OR}=27.1,95 \% \mathrm{CI}=1.43-513.05)$.
The frequency of $\mathrm{T}$ allele in the rs7556088 polymorphism, was not found to be statistically significant different between adenoma and MGD patients $(p=0.23, \quad \mathrm{OR}=0.68$, $95 \% \mathrm{CI}=0.38-1.21)$. However, it differed significantly when comparing adenoma or MGD patients with the control group $(p<0.0001, \mathrm{OR}=8.51,95 \% \mathrm{CI}=2.94-24.68$ and $p<0.0001$, $\mathrm{OR}=12.55,95 \% \mathrm{CI}=4.19-37.56$, respectively).

It is important to notice that blood specimens of the healthy control population were analyzed since, due to bioethical reasons, parathyroid tissue cannot be collected from healthy subjects. However, considering that the SNPs tested are germline polymorphisms, blood cells should also include these genetic alterations.

\section{Discussion}

The study hypothesis was that sPHPT resulting from single adenomas or multiple gland disease (MGD) incorporates different molecular pathways. This study attempted to evaluate the role of hsa-miR-30e and its SNPs in patients with sporadic parathyroid adenomas and MGD. Hsa-miR$30 \mathrm{e}$ has been associated with most of the genes reported by Morrison et al. and Velazquez et al $(9,20)$ to predict MGD (FOXG1B, SORBS1, NRXN3, ENC1, HNT, NRP1, MANBA, PHF16, ZMAT4, CDH1, HOOK1 and EGFR). These genes have been found to be involved in the pathogenesis of MGD but not in the development of 
adenoma $(9,20)$. In addition, MGD tumorigenesis has been associated with other genetic pathways that affect cell cycle regulation (PCNA gene), apoptosis (TRAIL, FAS, BCL-2, MDM2, P53, TBXA2R, FHIT, PTGDS, EGFR genes) and growth factor regulation (VEGF, FGF, TGF $\beta$, IGF-1 genes) (15). Hsa-miR-30e has been confirmed to target some of these genes according to multiple databases. In detail, FOXG1 (forkhead box G1) which is a transcription factor, acting as a repressor gene that affects tumorigenesis (25) is a target for hsa-miR-30e. In addition, NRXN3 (encoding neurexin 3 protein), NRP1 (neuropilin 1), PHF16 (PHD finger protein 16), $B C L 2$ (B-cell CLL/lymphoma protein 2), $F G F$ (fibroblast growth factor) and $I G F-1$ (insulin like growth factor 1) are also target genes for hsa-miR-30e. Considering that hsa-miR-30e targets all the aforementioned genes, the presence of hsa-miR-30e variants could cause genetic modifications by altering binding of miRNA on its target genes, resulting in the emergence of MGD. This hypothesis needs to be further studied.

Hsa-miR-30e has been found to have numerous SNPs as stated in genetic databases. The selection of the specific SNPs was based on the available literature data. In detail, recently $\mathrm{Xu}$ et al. described an association of variant ss 178077483 combined with rs7556088, with schizophrenia (26) and of variant ss178077483 with major depression disorder (27). Patients with PHPT may often suffer from atypical neuropsychiatric disorders ranging from mild cognitive disorders to severe psychosis (28). The presence of the hsa-miR-30e variants may imply the incidence of neuropsychiatric disorders in patients with PHP, however this hypothesis needs to be further examined.

Analysis of the expression of hsa-miR-30e revealed increased expression in patients with MGD compared to patients with adenomas. This is an important finding of our study as it implies that hsa-miR-30e may play a significant role in the pathogenesis of MGD, but this finding needs to be verified in further larger studies.

There is a paucity of studies investigating miRNA expression in parathyroid disease. To date, there is no other study specifically investigating differential expression of miRNAs in patients with sporadic adenomas and hyperplasia. Corbetta et al. have showed that miR-296, miR222, and miR-503 are overexpressed in parathyroid cancers compared to adenomas, signifying miR-296 as a potential oncosupressor gene implicated in the pathogenesis of parathyroid carcinoma (29). Likewise, Vaira et al. have demonstrated an up-regulation of miR517C and respective C19MC (a cluster on chromosome 19q13.4) alterations in parathyroid carcinomas compared to adenomas (30). Finally, Rahbari et al. have showed that miR-126*, miR-30b and miR-26b were dysregulated in parathyroid carcinomas compared to adenomas. In addition, they have found 22 uniquely expressed miRNAs in 15 sporadic primary parathyroid hyperplasia samples (21). Although detailed data were not presented in their paper, personal communication with the senior author confirmed that hsa-mir-30e was included in these miRNAs, showing that their findings were similar with our study.

On the other hand, SNPs ss 178077483 and rs7556088 of hsa-miR-30e gene were not found to differ significantly between tissue samples from adenoma and MGD patients. However, they were found to differ significantly between patients with sporadic PHPT and controls. A possible explanation may be that hsa-mir-30e over-expression could be associated with different SNP genotypes. This could not be assessed in our study due to the small number of samples and should be incorporated in future studies. Another explanation could be that MGD is a heterogenous group of pathologies incorporating diffuse hyperplasia, asymmetrical hyperplasia and double or triple adenomas. This certainly further complicates interpretations of our results.

There are several limitations in our study. The main one is the study of a single miRNA. Future studies should incorporate other miRNAs, as well. Another limitation is the complexity of distinguishing sporadic from hereditary disease. Known syndromic patients were excluded, but genetic testing was not routinely performed for all familial mutations of PHPT in all patients.

\section{Conclusion}

Knowing prior to parathyroidectomy surgery whether the patient has single or MGD is desirable. This most likely can be achieved with molecular and genetic criteria given the limitations of preoperative imaging and the fact that histological criteria remain controversial (15). In addition, recent literature has suggested the potential use of circulating miRNAs as diagnostic markers of malignancy (31). In view of these reports, our research will focus on the evaluation of the role of circulating miRNAs in the prediction of MGD in sPHPT and in patients with persistent and recurrent disease.

\section{Funding}

This project was funded by the Hellenic Endocrine Society.

\section{Conflicts of Interest}

There is no conflict of interest by any of the Authors.

\section{Authors' Contributions}

Maria Mizamtsidi: Data collection and interpretation, wrote the paper. Konstantonos Nastos: Conceived and designed the study, data collection and interpretation. Fausto Palazzo, Ioannis Vassiliou: Designed the study, contributed data, reviewed the manuscript. Vasilis Constantinides, Roberto Dina: Acquired and interpreted data, 
reviewed the manuscript. George Mastorakos: Designed the study, interpreted data, reviewed the manuscript. Megan Farenden: Collected and analysed data, performed the analysis. Maria Gazouli: Designed the study, analysed data and reviewed the manuscript.

\section{Acknowledgements}

This study was funded by the Hellenic Endocrine Society. The authors wish to thank $\mathrm{Dr}$ Electron Kebebew for providing unpublished data from the study of Rahbari et al. (21) that guided us for the selection of the miRNA studied, and useful comments on our work.

\section{References}

1 Canalejo A, Canalejo R, Rodriguez ME, Martinez-Moreno JM, Felsenfeld AJ, Rodríguez M and Almaden Y: Development of parathyroid gland hyperplasia without uremia: Role of dietary calcium and phosphate. Nephrol Dial Transplant 25(4): 10871097, 2009. PMID: 19934096. DOI: 10.1093/ndt/gfp616

2 Dubost C and Boucaut P: Differentiation between parathyroid adenoma and hyperplasia. Proof by peroperative wang floating test (author's transl). Nouv Presse Med 8(35): 2819-2820, 1979. PMID: 503811.

3 Pollice L and Resta L: Age dependent morphologic variations of parathyroid glands with a particular consideration of the hyperplasia (author's transl). Pathologica 72(1020): 501, 1980. PMID: 7465273.

4 Wang CA and Rieder SV: A density test for the intraoperative differentiation of parathyroid hyperplasia from neoplasia. Ann Surg 187(1): 63, 1978. PMID: 619801.

5 Marini F, Cianferotti L, Giusti F and Brandi ML: Molecular genetics in primary hyperparathyroidism: The role of genetic tests in differential diagnosis, disease prevention strategy, and therapeutic planning. A 2017 update. Clin Cases Miner Bone Metab 14(1): 60, 2017. PMID: 28740527. DOI: 10.11138/ $\mathrm{ccmbm} / 2017.14 .1 .060$

6 Thakker R: Genetics of parathyroid tumours. J Intern Med 280(6): 574-583, 2016. PMID: 27306766 DOI: 10.1111/ joim. 12523

7 Bednarz N, Blaut K, Sworczak K, Oseka T and Bielawski KP: The profile of erbb/her family genes copy number assessed by real-time pcr in parathyroid adenoma and hyperplasia associated with sporadic primary hyperparathyroidism. Acta Biochim Pol 56(1): 83-88, 2009. PMID: 19259547.

8 Yi Y, Nowak NJ, Pacchia AL and Morrison C: Chromosome 11 genomic changes in parathyroid adenoma and hyperplasia: Array cgh, fish, and tissue microarrays. Genes Chromosomes Cancer 47(8): 639-648, 2008. PMID: 18398822. DOI: 10.1002/ gcc. 20565

9 Velazquez-Fernandez D, Laurell C, Saqui-Salces M, Pantoja JP, Candanedo-Gonzalez F, Reza-Albarran A, Gamboa-Dominguez A and Herrera MF: Differential rna expression profile by cdna microarray in sporadic primary hyperparathyroidism (phpt): Primary parathyroid hyperplasia versus adenoma. World J Surg 30(5): 705-713, 2006. PMID: 16680586. DOI: 10.1007/s00268005-0708-3

10 Al-Maghrabi JA and Asa SL: Expression of nm23 antimetastatic gene product in parathyroid hyperplasia, adenoma and carcinoma.
An immunohistological assessment. Saudi Med J 26(5): 728-731, 2005. PMID: 15951858.

11 Uchino S, Noguchi S, Nagatomo M, Sato M, Yamashita H, Watanabe S, Murakami T, Toda M, Wakiya S and Adachi M: Absence of somatic ret gene mutation in sporadic parathyroid tumors and hyperplasia secondary to uremia, and absence of somatic men1 gene mutation in men2a-associated hyperplasia. Biomed Pharmacother 54(Suppl 1): 100s-103s, 2000. PMID: 10915003.

12 Erickson LA, Jin L, Wollan P, Thompson GB, van Heerden JA and Lloyd RV: Parathyroid hyperplasia, adenomas, and carcinomas: Differential expression of p27kip1 protein. Am J Surg Pathol 23(3): 288-295, 1999. PMID: 10078919.

13 Karak AK, Sarkar C, Chumber S and Tandon N: Mib-1 proliferative index in parathyroid adenoma \& hyperplasia. Indian J Med Res 105: 235-238, 1997. PMID: 9183080.

14 Kanematsu E, Matsui H, Deguchi T, Yamamoto O, Korematsu M, Kobayashi A, Nezasa SI, Yamamoto N, Takeuchi T, Tanaka $\mathrm{T}$ and Kawada Y: Significance of agnor counts for distinguishing carcinoma from adenoma and hyperplasia in parathyroid gland. Hum Pathol 28(4): 421-427, 1997. PMID: 9104941.

15 Mizamtsidi M, Nastos C, Mastorakos G, Dina R, Vassiliou I, Gazouli $\mathrm{M}$ and Palazzo F: Diagnosis, management, histology and genetics of sporadic primary hyperparathyroidism: Old knowledge with new tricks. Endocr Connect 7(2): R56-R68, 2018. PMID: 29330338. DOI: 10.1530/EC-17-0283

16 Link A, Schirrmeister W, Langner C, Varbanova M, Bornschein $\mathrm{J}$, Wex $\mathrm{T}$ and Malfertheiner P: Differential expression of micrornas in preneoplastic gastric mucosa. Sci Rep 5: 8270, 2015. PMID: 25652892. DOI: 10.1038/srep08270

17 Jin Y and Lee CG: Single nucleotide polymorphisms associated with microrna regulation. Biomolecules 3(2): 287-302, 2013. PMID: 24970168. DOI: 10.3390/biom3020287

18 Moszyńska A, Gebert M, Collawn JF and Bartoszewski R: Snps in microrna target sites and their potential role in human disease. Open Biol 7(4): 170019, 2017. PMID: 28381629. DOI: 10.1098/ rsob.170019

19 Liu C, Zhang F, Li T, Lu M, Wang L, Yue W and Zhang D: Mirsnp, a database of polymorphisms altering mirna target sites, identifies mirna-related snps in gwas snps and eqtls. BMC Genomics 13(1): 661, 2012. PMID: 23173617. DOI: 10.1186/ 1471-2164-13-661

20 Morrison C, Farrar W, Kneile J, Williams N, Liu-Stratton Y, Bakaletz A, Aldred MA and Eng C: Molecular classification of parathyroid neoplasia by gene expression profiling. Am J Pathol 165(2): 565-576, 2004. PMID: 15277230. DOI: 10.1016/S00029440(10)63321-4

21 Rahbari R, Holloway AK, He M, Khanafshar E, Clark OH and Kebebew E: Identification of differentially expressed microrna in parathyroid tumors. Ann Surg Oncol 18(4): 1158-1165, 2011. PMID: 21086055. DOI: 10.1245/s10434-010-1359-7

22 Pikor LA, Enfield KS, Cameron $\mathrm{H}$ and Lam WL: DNA extraction from paraffin embedded material for genetic and epigenetic analyses. J Vis Exp 49, 2011. PMID: 21490570. DOI: $10.3791 / 2763$

23 Tang F, Hajkova P, Barton SC, O'carroll D, Lee C, Lao K and Surani MA: 220-plex microrna expression profile of a single cell. Nat Protoc 1(3): 1154, 2006. PMID: 17406397. DOI: 10.1038/nprot.2006.161

24 Xu Y, Li F, Zhang B, Zhang K, Zhang F, Huang X, Sun N, Ren Y, Sui $\mathrm{M}$ and Liu P: Micrornas and target site screening reveals 
a pre-microrna-30e variant associated with schizophrenia Schizophr Res 119(1-3): 219-227, 2010. PMID: 20347265. DOI: 10.1016/j.schres.2010.02.1070

25 Manoranjan B, Wang X, Hallett RM, Venugopal C, Mack SC, McFarlane N, Nolte SM, Scheinemann K, Gunnarsson T and Hassell JA: Foxg1 interacts with bmil to regulate self-renewal and tumorigenicity of medulloblastoma stem cells. Stem Cells 31(7): 1266-1277, 2013. PMID: 23592496. DOI: 10.1002/ stem.1401

26 Xu Y, Li F, Zhang B, Zhang K, Zhang F, Huang X, Sun N, Ren $\mathrm{Y}$, Sui $\mathrm{M}$ and Liu P: Micrornas and target site screening reveals a pre-microrna-30e variant associated with schizophrenia. Schizophr Res 119(1-3): 219-227, 2010. PMID: 20347265. DOI: 10.1016/j.schres.2010.02.1070

27 Xu Y, Liu H, Li F, Sun N, Ren Y, Liu Z, Cao X, Wang Y, Liu P and Zhang $\mathrm{K}$ : A polymorphism in the microrna-30e precursor associated with major depressive disorder risk and p300 waveform. J Affect Disord 127(1-3): 332-336, 2010. PMID: 20579744. DOI: 10.1016/j.jad.2010.05.019

28 Parks KA, Parks CG, Onwuameze OE and Shrestha S: Psychiatric complications of primary hyperparathyroidism and mild hypercalcemia. Am J Psychiatry 174(7): 620-622, 2017. PMID: 28669204. DOI: 10.1176/appi.ajp.2017.16111226
29 Corbetta S, Vaira V, Guarnieri V, Scillitani A, Eller-Vainicher C, Ferrero S, Vicentini L, Chiodini I, Bisceglia M, Beck-Peccoz P, Bosari S and Spada A: Differential expression of micrornas in human parathyroid carcinomas compared with normal parathyroid tissue. Endocr Relat Cancer 17(1): 135-146, 2010. PMID: 19926710. DOI: 10.1677/ERC-09-0134

30 Vaira V, Elli F, Forno I, Guarnieri V, Verdelli C, Ferrero S, Scillitani A, Vicentini L, Cetani F, Mantovani G, Spada A, Bosari S and Corbetta S: The microrna cluster c19mc is deregulated in parathyroid tumours. J Mol Endocrinol 49(2): 115-124, 2012. PMID: 22767050. DOI: 10.1530/JME-11-0189

31 Madhavan D, Cuk K, Burwinkel B and Yang R: Cancer diagnosis and prognosis decoded by blood-based circulating microrna signatures. Front Genet 4: 116, 2013. PMID: 23802 013. DOI: $10.3389 /$ fgene. 2013.00116
Received March 21, 2019

Revised May 14, 2019

Accepted May 20, 2019 